\title{
Analyses of Effects of Cutting Parameters on Cutting Edge Temperature Using Inverse Heat Conduction Technique
}

\author{
Marcelo Ribeiro dos Santos, ${ }^{1}$ Sandro Metrevelle Marcondes de Lima e Silva, ${ }^{2}$ \\ Álisson Rocha Machado, ${ }^{1}$ Márcio Bacci da Silva, ${ }^{1}$ Gilmar Guimarães, ${ }^{1}$ \\ and Solidônio Rodrigues de Carvalho' \\ ${ }^{1}$ College of Mechanical Engineering, Federal University of Uberlândia, Campus Santa Mônica, Bloco M, \\ Avenida João Naves de Ávila 2121, 38408-100 Uberlândia, MG, Brazil \\ ${ }^{2}$ Institute of Mechanical Engineering, Federal University of Itajubá, Campus Professor José Rodrigues Seabra, \\ Avenida BPS 1303, 37500-903 Itajubá, MG, Brazil
}

Correspondence should be addressed to Solidônio Rodrigues de Carvalho; srcarvalho@mecanica.ufu.br

Received 17 February 2014; Revised 2 April 2014; Accepted 23 April 2014; Published 1 June 2014

Academic Editor: Caner Özdemir

Copyright (C) 2014 Marcelo Ribeiro dos Santos et al. This is an open access article distributed under the Creative Commons Attribution License, which permits unrestricted use, distribution, and reproduction in any medium, provided the original work is properly cited.

\begin{abstract}
During machining energy is transformed into heat due to plastic deformation of the workpiece surface and friction between tool and workpiece. High temperatures are generated in the region of the cutting edge, which have a very important influence on wear rate of the cutting tool and on tool life. This work proposes the estimation of heat flux at the chip-tool interface using inverse techniques. Factors which influence the temperature distribution at the AISI M32C high speed steel tool rake face during machining of a ABNT 12L14 steel workpiece were also investigated. The temperature distribution was predicted using finite volume elements. A transient 3D numerical code using irregular and nonstaggered mesh was developed to solve the nonlinear heat diffusion equation. To validate the software, experimental tests were made. The inverse problem was solved using the function specification method. Heat fluxes at the tool-workpiece interface were estimated using inverse problems techniques and experimental temperatures. Tests were performed to study the effect of cutting parameters on cutting edge temperature. The results were compared with those of the tool-work thermocouple technique and a fair agreement was obtained.
\end{abstract}

\section{Introduction}

Nowadays, several researchers proposed the combination of inverse techniques and analytical or numerical heat transfer solutions to analyze the thermal fields during machining processes. One method to study the heat transfer problem is to adopt a known heat flux and calculate the temperature at the chip-tool interface from the solution of the heat diffusion equation. In literature, this methodology is called direct problem in heat transfer. However, during machining the experimental heat flux is unknown and inverse techniques have to be used to predict this parameter. This proposal estimates the transient heat flux with a numerical model based on the heat diffusion equation using inverse techniques and experimental temperatures measured at accessible regions of the sample.
In Chen et al. [1] the inverse technique used was based on the sequential function specification method proposed by Beck et al. [2]. The numerical technique used was the finite volume method and the temperatures were obtained by inserting a thermocouple in the tool. In both methods the model took into account only the insert and some discrepancies were observed between calculated and measured temperatures.

Lazard and Corvisier [3] considered the problem of estimating the transient temperature and the heat flux at the chip-tool interface during a turning process using an inverse approach. The heat transfer model was based on a quadrupole formulation commonly used to solve ordinary differential equations in the Laplace domain. The results of temperature obtained with the analytical model used were 


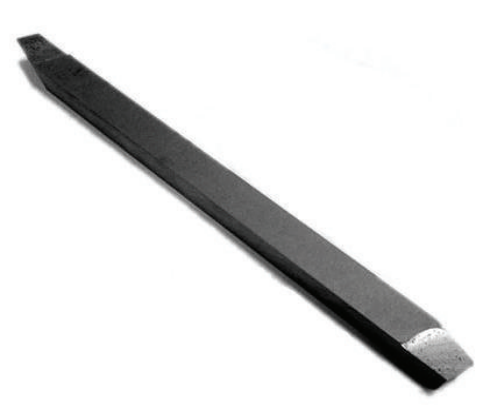

(a)

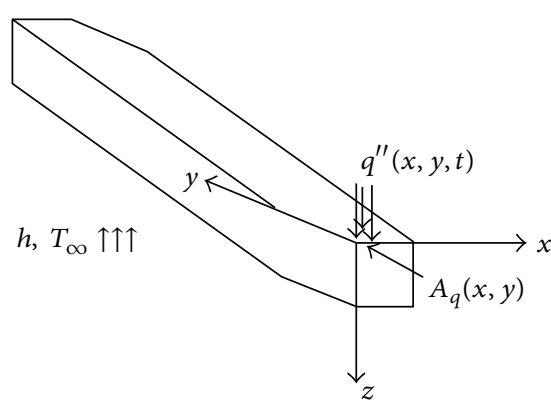

(b)

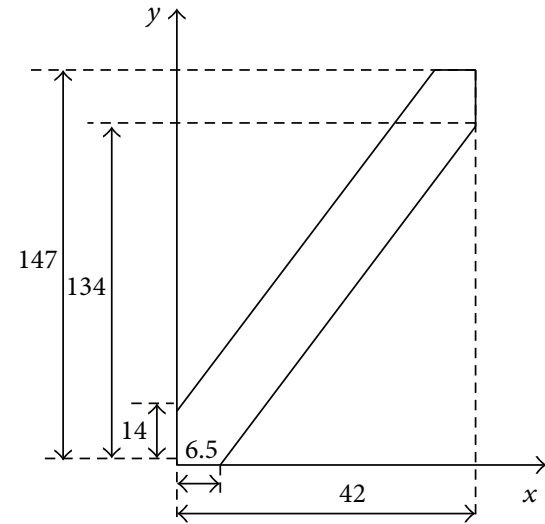

(c)

FiguRE 1: (a) High speed steel tool, (b) three-dimensional physical model, and (c) tool dimensions in millimeters (mm) where the coordinate " $z$ " is $9.5(\mathrm{~mm})$.

in good agreement with those obtained with FLUENT. The authors assumed that the temperature measurements were available for the inverse analysis.

In the work of Yvonnet et al. [4] an innovative approach was proposed. The work was based on a simple inverse procedure to identify both the heat flux flowing into the tool through the rake face and the heat transfer coefficient between the tool and the environment during a typical orthogonal cutting process. To determine the heat flux and convection heat transfer coefficient, an iterative NewtonRaphson procedure was used to minimize the error defined by the difference between experimental and calculated temperatures. Four different tools were used; three of them were manufactured by electrical discharge machining (EDM) cutting the last slot with different distances between the tool tip and the slot: $0.35,0.50$, and $0.60 \mathrm{~mm}$. The last tool was instrumented with a thermocouple to measure the average heat flux flowing into the tool through the rake face.

Woodbury et al. [5] demonstrated the solution of a threedimensional inverse heat conduction problem using an evolutionary algorithm (EA). The heat flux from the workpiece into the tool during the turning process was determined using evolutionary operations combined with measurements of surface temperature on the tool. The three-dimensional conduction in the tool and tool holder was simulated using FLUENT.

A numerical prediction of the three-dimensional temperature fields in moving chip, stationary tool, and moving workpiece during machining operations using a finite difference method was presented in Ulutan et al. [6]. First, the authors studied the chip and tool together to create a heat balance due to the friction on the rake face. Then, an investigation of the effect of the chip and tool interface temperature on the temperature field of the workpiece, taking into account the heat generated at the shear plane, was made. A finite difference model was employed to describe the process, and the results were in good agreement with experimental data presented in the literature. The advantage of this method in relation to finite element method (FEM) models is the computational time, which decreased substantially, and the advantage in relation to curve fitting methods is that the method is based on the physical phenomenon.

In Samadi et al. [7] the sequential function specification method was used with simulated temperature data to estimate the transient heat flux imposed on the rake face of a cutting tool during the cutting operation with two different hypotheses. The thermal conductivity was considered constant in one, and in the other it varied with temperature. The cutting tool was modeled as a three-dimensional object. The influence of nonlinearity and different sensor locations were investigated in order to determine an optimal experimental procedure. Finally, typical temperature data during turning was used to recover the heat flux at the cutting tool surface considering linear and nonlinear solutions.

The aim of the present paper is to estimate the heat flux and calculate the temperature field at the cutting interface of the high speed steel tool. In addition, the influence of the cutting parameters (cutting speed, cutting depth, and feed rate) on the tool-chip interface temperature was also investigated. The novelty in this work, compared to others presented in the literature, is the joint solution and analysis of the following problems: a nonlinear tridimensional thermal model, an inverse technique to estimate the heat flux, the thermal analyses of a machining process, and the final comparison of the results with those obtained from a fully experimental methodology proposed to Evangelista Luiz [8] based on the tool-workpiece thermocouple technique (TWTT).

\section{The Direct Problem: Thermal Model}

Figure 1 shows the high speed steel tool, the model used, and the dimensions of the tool. The interface contact area $A_{q}(x, y)$ was subjected to the heat flux $q^{\prime \prime}(x, y, t)$ generated by contact between the tool and the workpiece. At the remaining boundaries a constant convective heat transfer coefficient of $20\left(\mathrm{~W} / \mathrm{m}^{2} \mathrm{~K}\right)$ was considered.

The three-dimensional physical problem was solved in Cartesian coordinates, using finite volume technique with 
TABLE 1: Thermal properties of high speed steel tool according to Taylor Specials Steels Ltda (2009). Material: AISI M32 C, with 10\% of cobalt.

\begin{tabular}{lcc}
\hline Temperature range $\left({ }^{\circ} \mathrm{C}\right)$ & $0 \leq T \leq 400$ & $T>400$ \\
Thermal conductivity $(\mathrm{W} / \mathrm{mK})$ & $0.0105 T+23.8$ & $-0.005 T+30$ \\
Thermal diffusivity $\left(\mathrm{m}^{2} / \mathrm{s}\right)$ & $-5.03 \times 10^{-10} T+7.02 \cdot 10^{-6}$ & $-5.94 \times 10^{-9} \cdot T+9.19 \times 10^{-6}$ \\
\hline
\end{tabular}

irregular mesh. The objective is to obtain the temperature distribution in the tool using the direct problem and in following estimate the heat flux generated at the chip-tool interface with inverse techniques.

The choice of the high speed steel tool is due to its large application in industry and also because Evangelista Luiz [8] presented a thermal analysis using tool/work thermocouple technique (TWTT), thus permitting the comparison with the results obtained using a different technique.

The thermal problem shown in Figure 1(b) is described by the heat diffusion equation as in Carvalho et al. [9]:

$$
\frac{\partial}{\partial x}\left(\lambda \frac{\partial T}{\partial x}\right)+\frac{\partial}{\partial y}\left(\lambda \frac{\partial T}{\partial y}\right)+\frac{\partial}{\partial z}\left(\lambda \frac{\partial T}{\partial z}\right)=\rho C \frac{\partial T}{\partial t}
$$

The boundary conditions imposed are

$$
-\lambda \frac{\partial T}{\partial \eta}=h\left(T-T_{\infty}\right)
$$

at the regions exposed to the environment and

$$
-\lambda \frac{\partial T}{\partial \eta}=q^{\prime \prime}(x, y, t)
$$

at the interface defined by $A_{q}$, where $\eta$ is the outward normal in coordinates $x, y$, and $z$; $T$ is the temperature; $T_{\infty}$ is the room temperature; $\lambda$ is the thermal conductivity; $\rho C$ is the volumetric heat capacity; and $h$ the heat transfer coefficient. The initial condition is given by

$$
T(x, y, z, 0)=T_{o}
$$

where $T_{o}$ is the initial temperature of the tool, shim, and tool holder.

The above equations were implemented in $\mathrm{C}++$. An algorithm called Inverse3D or Inv3D was developed. This computational algorithm has been developed over the last 14 years by the research group of the Laboratory of Heat and Mass Transfer, College of Mechanical Engineering, Federal University of Uberlândia. It has been extensively validated and has led to several articles published in scientific journals and conferences, such as Brito et al. [10], Brito et al. [11], Sousa et al. [12] and Carvalho et al. [9].

The thermal properties of the tool obtained from Taylor Special Steels Ltd. [13] are shown in Table 1.

Several factors are responsible for the errors or uncertainties in the mathematical model. Comparing Figures 1(a) and $1(\mathrm{~b})$, there are several simplifications in geometry of the thermal model compared to the cutting tool. The model did not include the rake and relief angles typical of any cutting tool. Such simplifications imply an increase in volume of the model of $1.47 \%$ compared to the tool. In spite of this small increase, no significant changes were identified in the thermal field calculated by the model of the cutting tool.
As for the uncertainties in the thermal model, the thermal properties of the tool were obtained from scientific papers. Other sources of uncertainties are the correct location of the thermocouples and the presence of noise in the experimental signal of the temperature. In this work, we opted for the technique of capacitive discharge to weld the thermocouples to the tool, thus minimizing uncertainty regarding the thermal contact resistance.

An HP 75000, series B, data acquisition system with E1326B voltmeter controlled by a PC, connected to a stabilized power source, was used. The temperature acquisition interval was 0.25 seconds. Based on the procedures and the equipment adopted, it was estimated that the measurement error of the entire system (thermocouple/multimeter) was less than $\pm 0.3^{\circ} \mathrm{C}$.

Also an average $h$ of $20 \mathrm{~W} / \mathrm{m}^{2} \mathrm{~K}$ for the entire surface of the tool was used. The correct determination of the heat transfer coefficient by convection is not an easy task. An analysis of the influence of this important parameter on the calculated temperature at the cutting interface is shown in Figure 2.

Figure 2(a) shows that the heat transfer coefficients by convection $(h)$ in the range tested $\left(10-30 \mathrm{~W} / \mathrm{m}^{2} \mathrm{~K}\right)$ has little influence on the final temperature at the cutting interface. Adopting an average $h$ of $20 \mathrm{~W} / \mathrm{m}^{2} \mathrm{~K}$ as reference and comparing the calculated temperature with those obtained for other values of $h$ a maximum deviation of less than $0.74 \%$ was obtained during machining as shown in Figure 2(b). With this result, it was concluded that for the range of values of $h$ considered, the calculation of the temperature at the cutting interface was not compromised. Hence the value of $20 \mathrm{~W} / \mathrm{m}^{2} \mathrm{~K}$ was adopted.

Figure 3 shows the heat transfer rate by convection at the cutting interface for different values of $h$.

Figure 3 shows that as $h$ increases, the rate of heat transfer becomes more significant. Besides, within the range of values analyzed $\left(10-30 \mathrm{~W} / \mathrm{m}^{2} \mathrm{~K}\right)$ a maximum difference of only $1 \mathrm{~W}$ in relation to $h=20 \mathrm{~W} / \mathrm{m}^{2} \mathrm{~K}$ occurred. Thus, it is concluded that $h$ has little influence on the interface temperature. The energy lost by convection represents $6.1 \%$ of the energy generated at the cutting interface $\left(h=20 \mathrm{~W} / \mathrm{m}^{2} \mathrm{~K}\right)$.

\section{The Inverse Problem: Function Specification Procedure}

The inverse technique adopted in this work is the Sequential Function Estimation, Beck's Method [2]. This technique requires the sensitivity coefficients $(\phi)$, which are the derivatives of the calculated temperatures $(T)$ with respect to the heat flux $\left(q^{\prime \prime}\right)$. 


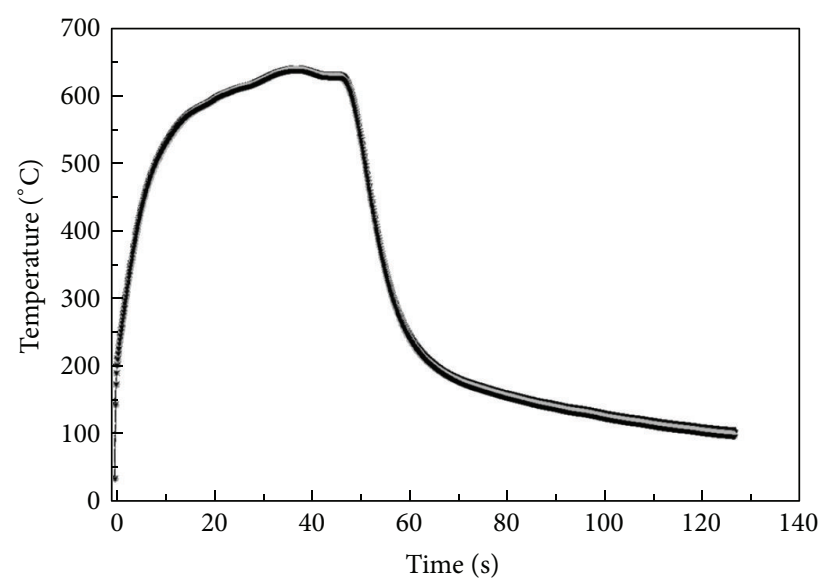

$$
\begin{aligned}
& \rightarrow h=10\left(\mathrm{~W} / \mathrm{m}^{2} \mathrm{~K}\right) \quad \longrightarrow h=22\left(\mathrm{~W} / \mathrm{m}^{2} \mathrm{~K}\right) \\
& -+-h=18\left(\mathrm{~W} / \mathrm{m}^{2} \mathrm{~K}\right) \quad \cdots-h=30\left(\mathrm{~W} / \mathrm{m}^{2} \mathrm{~K}\right) \\
& -x-h=20\left(\mathrm{~W} / \mathrm{m}^{2} \mathrm{~K}\right)
\end{aligned}
$$

(a)

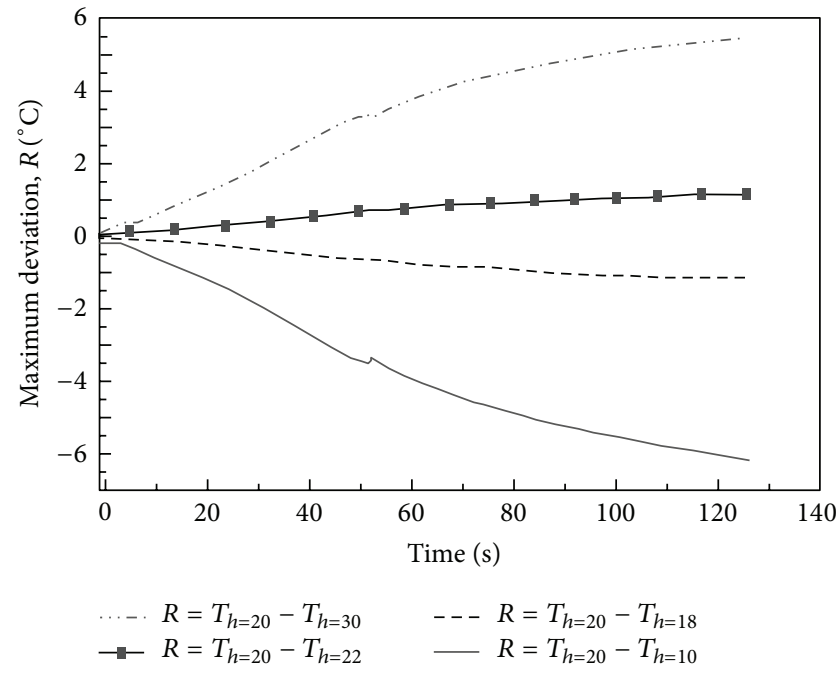

(b)

Figure 2: Analysis of the influence of the heat transfer coefficient by convection: (a) cutting interface temperature for different values of $h$ and (b) analysis of uncertainty considering $h=20 \mathrm{~W} / \mathrm{m}^{2} \mathrm{~K}$ as reference. Cutting conditions: feed rate: $0.138 \mathrm{~mm} / \mathrm{rot}$, cutting speed: $142 \mathrm{~m} / \mathrm{min}$ (900 rpm), and depth of cut: $1.0 \mathrm{~mm}$.

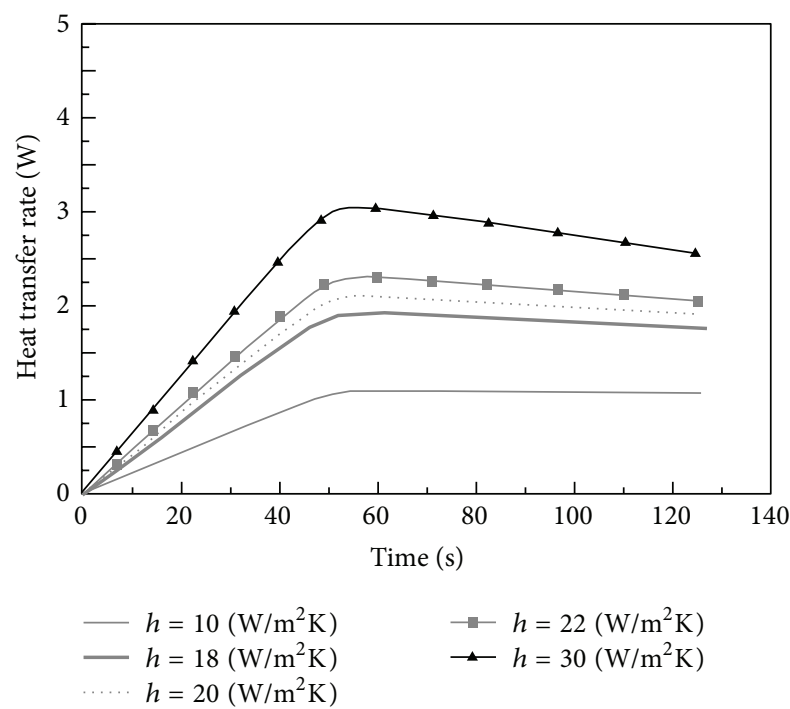

FIGURE 3: Heat transfer rate by convection for different values of $h$. Cutting conditions: feed rate: $0.138 \mathrm{~mm} /$ rot, cutting speed: $142 \mathrm{~m} / \mathrm{min}$ (900 rpm), and depth of cut: $1.0 \mathrm{~mm}$.

Numerically, the sensitivity coefficients $(\phi)$ were calculated at the thermocouples positions (Table 2) as shown in Figure 4(a). The direct problem is solved considering (1), with $q^{\prime \prime}=1$ (unit value), initial temperature equal to zero $(T=$ 0 ), $h$ equal to $20 \mathrm{~W} / \mathrm{m}^{2} \mathrm{~K}$, and constant thermal properties calculated for $T=30^{\circ} \mathrm{C}$ using Table 1 . The numerical technique is based on Duhamel's summation and Stolz method [2].

Basically, the Sequential Function Estimation minimizes a squared error function based on numerical $(T)$ and experimental temperatures $(Y)$, to estimate the heat flux $\left(q^{\prime \prime}\right)$ at
TABLE 2: Thermocouple locations following the coordinate system defined in Figure 1.

\begin{tabular}{lccccc}
\hline \multirow{2}{*}{ Position } & \multicolumn{5}{c}{ Thermocouple } \\
& 1 & 2 & 3 & 4 & 5 \\
\hline$x(\mathrm{~mm})$ & 0.61 & 2.70 & 0.0 & 3.30 & 2.00 \\
$y(\mathrm{~mm})$ & 7.20 & 8.50 & 9.0 & 7.00 & 3.40 \\
$z(\mathrm{~mm})$ & 0.0 & 0.0 & 5.0 & 9.50 & 9.50 \\
\hline
\end{tabular}

chip-tool contact area for each time step $(M)$. The basic idea is to reduce a continuous function to a set of parameters by specifying an underlying nature of the function. In this work a constant sequential function was adopted. Thus, according to Beck et al. [2], the heat flux can be estimated as given in

$$
q_{M}^{\prime \prime}=\frac{\sum_{i=1}^{r} \sum_{j=1}^{J}\left(Y_{j, M+i-1}-\widehat{T}_{j, M+i-1 \mid q_{M=\cdots=0}}\right) \phi_{j i}}{\sum_{i=1}^{r} \sum_{j=1}^{J} \phi_{j i}{ }^{2}},
$$

where $M$ is the time, $J$ is the number of sensors, $r$ is the number of future time steps, and $Y$ and $T$ are the experimental and calculated temperatures, respectively.

In the estimation process 10 future time steps were used for each cutting condition. The transient heat flux for each experiment was estimated as shown in Figure 4(b).

Finally, according to Figure $4(\mathrm{c})$ the direct problem is again solved considering the nonlinear thermal model (1) in which the thermal properties vary with temperature, resulting in the temperature distribution in the cutting tool.

\section{Experimental Procedure}

The machining test was carried out in a conventional IMOR MAXI-II-520-6CV lathe without coolant. The material used 


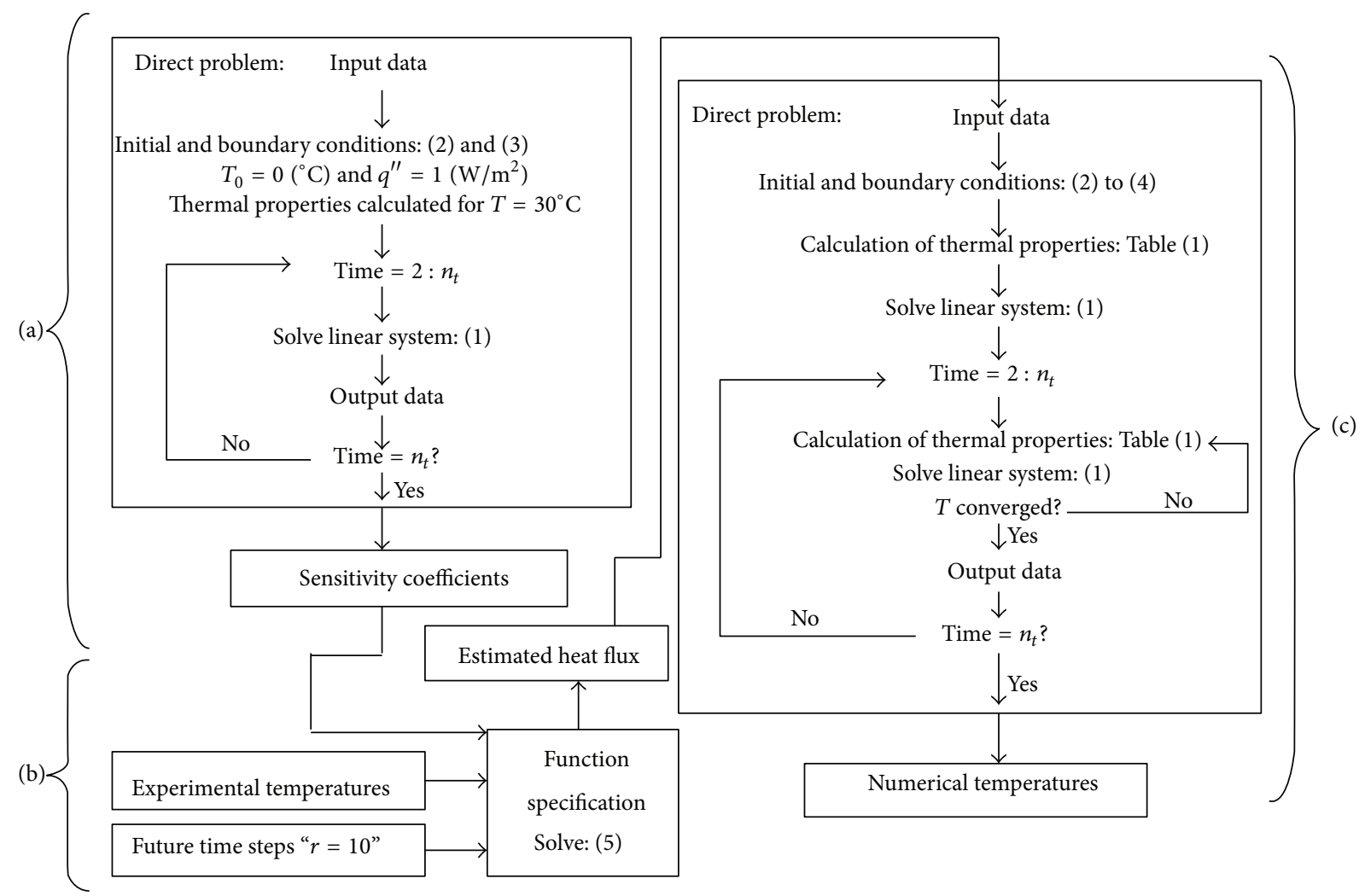

FIgURE 4: Computational algorithm: (a) calculation of the sensitivity coefficients; (b) Beck's method for the solution of the inverse problem; (c) solution of the nonlinear thermal model.

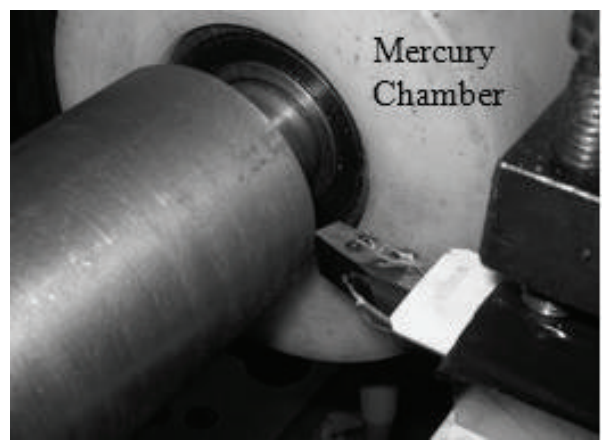

(a)

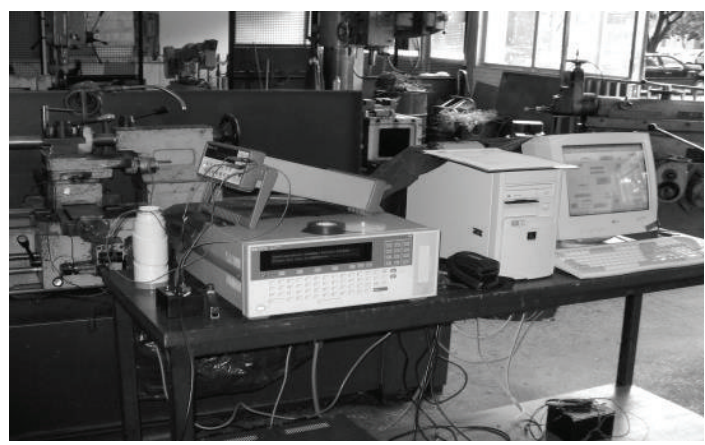

(b)

FIGURE 5: (a) Thermocouples on the tool and (b) equipment.

in the experimental tests was cylindrical ABNT 12L14 [8] bars with an external diameter of $50.2 \mathrm{~mm}$. Figure 5 shows the temperatures measured at accessible locations of the insert using type $\mathrm{T}$ thermocouples and an HP 75000, series $\mathrm{B}$, data acquisition system with an E1326B voltmeter controlled by a PC.

Table 2 gives the thermocouple locations according to the coordinate system shown in Figure 1. To evaluate the influence of the machining parameters-depth of cut $(a p)$, feed rate $(f)$, and cutting speed $(V c)$ - on temperature at chiptool interface, the following tests given in Tables 3, 4, and 5 were made.

The chip-tool contact area of each test was defined by an imaging system. The device consists of a Hitachi model
TABLE 3: Depth of cut (constant parameters: $f=0.138 \mathrm{~mm} /$ rot and $V c=56 \mathrm{~m} / \mathrm{min}$ )

\begin{tabular}{lllll}
\hline & \multicolumn{4}{c}{ Unit $(\mathrm{mm})$} \\
\hline$a p$ & 0.5 & 1.0 & 1.5 & 2.0 \\
\hline
\end{tabular}

KP-110 CCD video camera, an AMD K6 $450 \mathrm{MHz}$ computer, and a software processer of images (the Global Lab Image). Figure 6 shows a photograph of the contact area $\left(A_{q}=L \cdot H\right)$ for cutting conditions: $a p=1.0 \mathrm{~mm}, f=0.138 \mathrm{~mm} / \mathrm{rot}$, and $V c=56 \mathrm{~m} / \mathrm{min}$ (scale $25: 1$ ).

Figure 7 shows the results of the chip-tool contact areas for the cutting conditions of Tables 3 to 5 . 


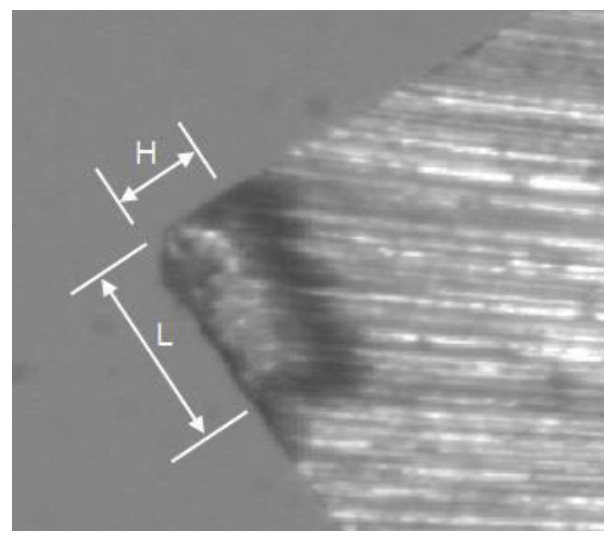

Figure 6: Chip-tool contact area for cutting conditions: $a p=1.0 \mathrm{~mm} ; f=0.138 \mathrm{~mm} / \mathrm{rot}$ and; $V c=56 \mathrm{~m} / \mathrm{min} ;$ scale $25: 1$.

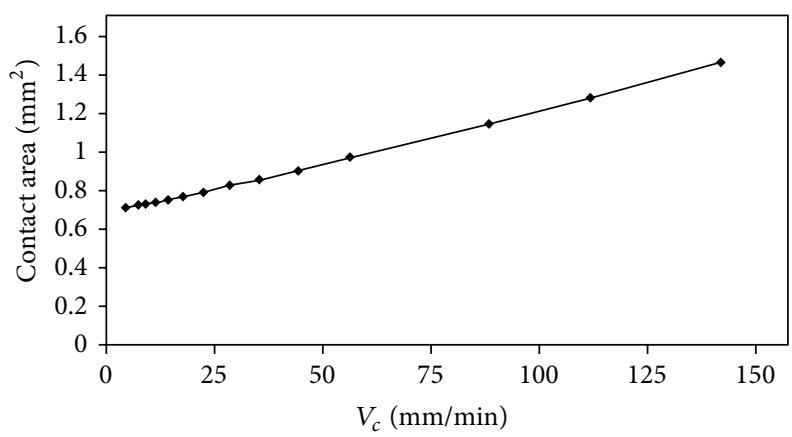

(a)

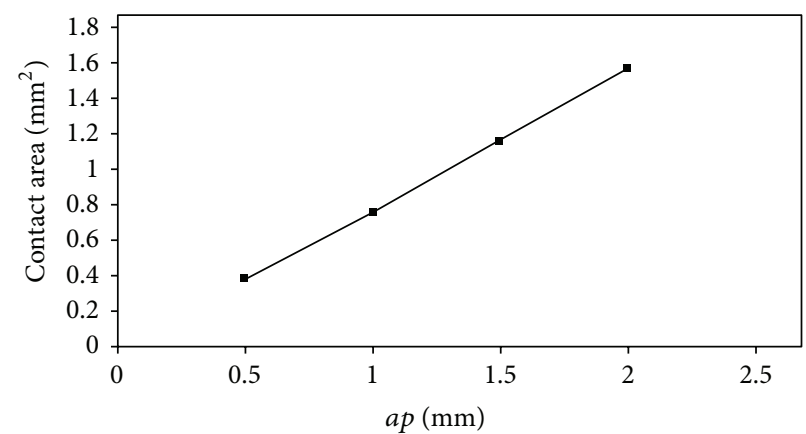

(b)

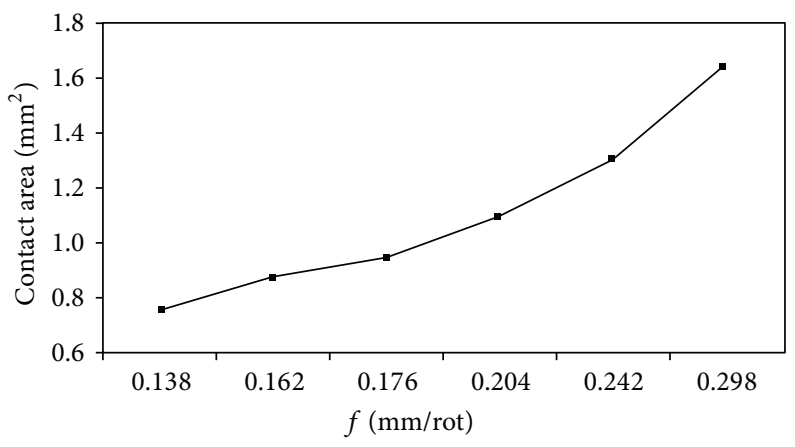

(c)

Figure 7: Chip-tool contact area for the following conditions: (a) $a p=1.0 \mathrm{~mm}, f=0.138 \mathrm{~mm} / \mathrm{rot}$, and $V c$ variable; (b) $f=0.138 \mathrm{~mm} / \mathrm{rot}$, $V c=56 \mathrm{~m} / \mathrm{min}$, and $a p$ variable; (c) $a p=1.0 \mathrm{~mm}, V c=56 \mathrm{~m} / \mathrm{min}$, and $f$ variable.

TABLE 4: Feed rate (constant parameters: $a p=1.0 \mathrm{~mm}$ and $V c=$ $56 \mathrm{~m} / \mathrm{min})$.

\begin{tabular}{lllllll}
\hline \multicolumn{7}{c}{ Unit $(\mathrm{mm} /$ rot $)$} \\
\hline$f$ & 0.138 & 0.162 & 0.176 & 0.204 & 0.242 & 0.298 \\
\hline
\end{tabular}

Increase of the cutting parameters increases the chiptool contact area. The development of an accurate method to measure the chip-tool contact area represents a great challenge because direct observations during cutting are not possible. Most of the available theories of the identification of the chip-tool contact area are derived from the study of the interface after cutting had been interrupted. In this work, the methodology is also based on the analysis of the contact area after cutting. However, even with the enlarged areas from analysis software, identification of the contact area is not an easy task and requires experience and knowledge of the researcher. Normally approximate areas are obtained because even with the various existing theories it is difficult or even impossible to identify the real chip-tool contact area.

In this work, the area was approximated as a rectangle, in which the energy is distributed evenly. Thus,

$$
q^{\prime \prime}(x, y, t)=q^{\prime \prime}(t) .
$$




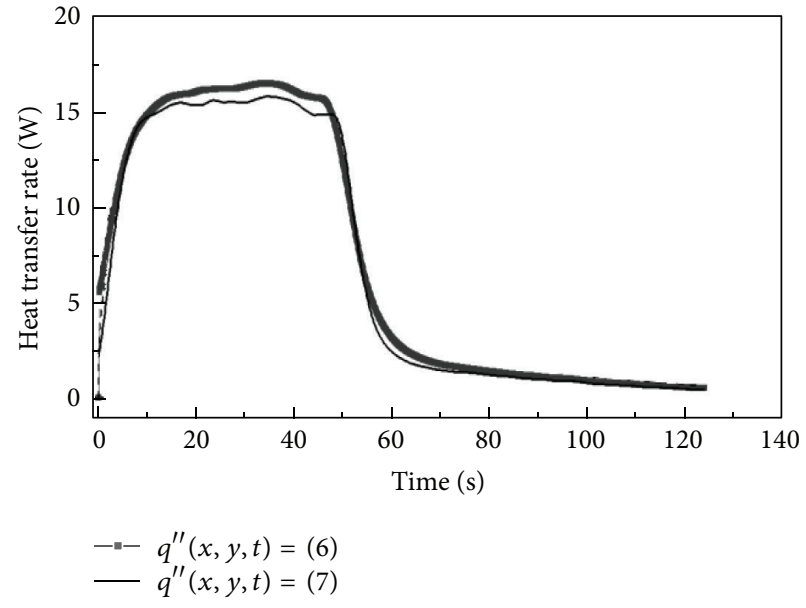

(a)

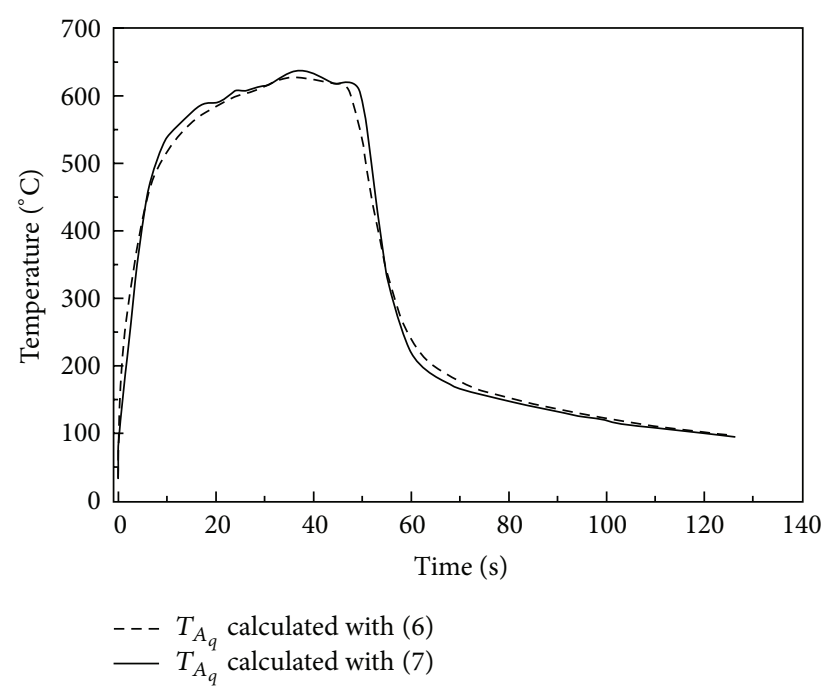

(b)

Figure 8: (a) Comparison of the average heat transfer rates and (b) temperatures at the cutting interface.

TABLE 5: Cutting speed (constant parameters: $a p=1.0 \mathrm{~mm}$ and $f=0.138 \mathrm{~mm} / \mathrm{rot}$ ).

\begin{tabular}{|c|c|c|c|c|c|c|c|c|c|c|c|c|c|c|}
\hline & \multicolumn{14}{|c|}{ Unit (m/min) } \\
\hline$V c$ & 4.4 & 7.1 & 8.8 & 11.2 & 14.2 & 17.7 & 22.1 & 28.4 & 35.3 & 44.2 & 56 & 88.3 & 112 & 142 \\
\hline
\end{tabular}

However, metallographic techniques such as those applied by Dearnley [14] showed that the correct methodology would be to adopt an irregular area and a nonuniform heat flux distribution at the cutting interface. However, the combination of both parameters in the thermal model, that is, irregular heat flux and irregular area, would lead to countless possible results. Thus, as the area had been previously measured, it was decided to change only the distribution of the heat flux at the cutting interface. The thermal model was simulated in two stages: initially a uniform heat flux at the cutting interface was adopted (6), and in the following stage, an exponential heat flux was used, as in

$$
q^{\prime \prime}(x, y, t)=q_{a}^{\prime \prime} \cdot e^{\left(-1 / l_{x}^{2}\right) \cdot\left(x-x_{o}\right)^{2}+\left(-1 / l_{y}^{2}\right) \cdot\left(y-y_{o}\right)^{2}}
$$

The variables $x$ and $y$ define the coordinates of the contact area, $q_{a}^{\prime \prime}$ is the maximum value of instantaneous heat flux at the contact area, $l_{x}$ and $l_{y}$ are the dimensions of the contact area, and $x_{0}$ and $y_{0}$ are the points of maximum value. The variables $l_{x}, l_{y}, x_{o}$, and $y_{o}$ were adjusted for each cutting condition, using the contact areas shown in Figure 7.

Thus, with the cutting parameters, the chip-tool contact area, and the experimental temperatures measured for each case, this work proposes to solve the inverse problem, estimate the heat flux at the interface, and obtain the threedimensional temperature distribution in the tool. The results were compared with those obtained by the experimental toolwork thermocouple method [8].

\section{Results and Discussions}

Figure 8 shows the heat transfer rate and the average temperature at the cutting interface during the most severe cutting condition: feed rate $f=0.138 \mathrm{~mm} /$ rot, cutting speed $V c=$ $142 \mathrm{~m} / \mathrm{min}$ (900 rpm), and cutting depth $a p=1.0 \mathrm{~mm}$.

Figure $8(\mathrm{a})$ shows that the average heat transfer rate estimated with an exponential heat flux (7) is quite similar to that estimated with a uniform heat flux (6). Consequently the average temperatures at the cutting interface are quite similar (Figure 8(b)).

Figure 9 shows a comparison of experimental and calculated temperatures of each methodology.

Figure 9(a) shows good agreement between calculated and experimental temperatures. However, Figure 9(b) shows that the residue is lower for temperatures calculated with exponential heat flux (7).

Figure 10 shows the temperature profile in the tool for the following cutting conditions: feed rate $f=0.138 \mathrm{~mm} / \mathrm{rot}$, cutting speed $V c=142 \mathrm{~m} / \mathrm{min}(900 \mathrm{rpm})$, and cutting depth $a p=1.0 \mathrm{~mm}$, where the maximum temperature calculated at the chip-tool interface was $600^{\circ} \mathrm{C}$.

Analyzing Figures 10(b) and 10(c) the isotherms in a real machining process tend to behave as shown in Figure 10(c); that is, the maximum temperature in the contact area is at a certain distance from the main cutting edge as found in the literature, such as Dearnley [14]. Thus the use of an exponential heat flux gives results more consistent with those identified in a real turning process. 


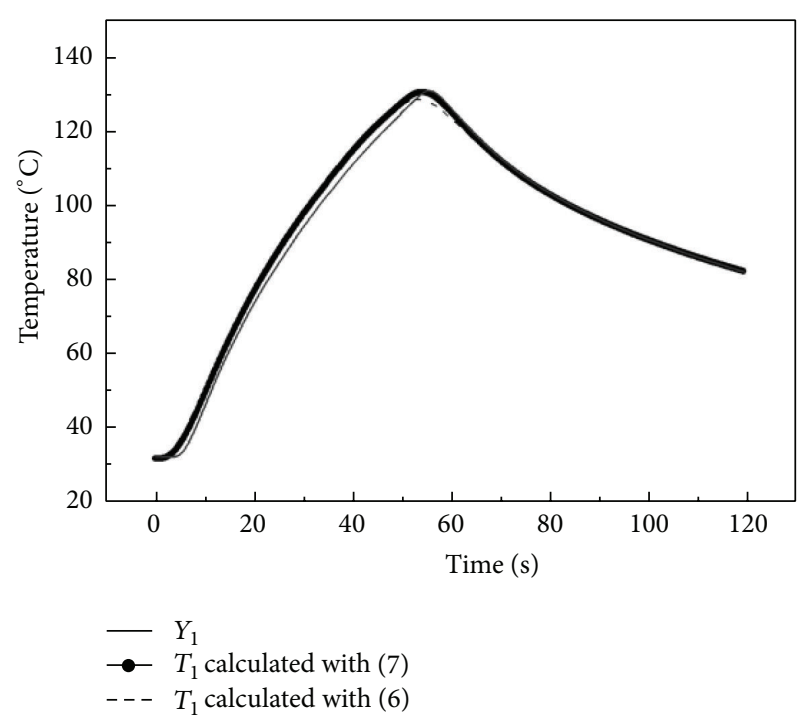

(a)

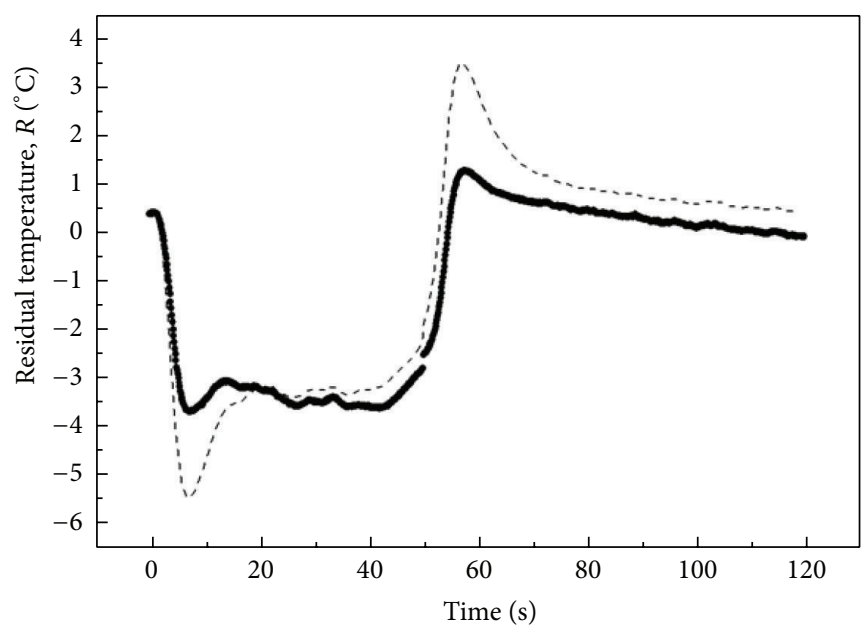

$\rightarrow R=Y_{1}-T_{1}$ calculated with (7)

-- - $R=Y_{1}-T_{1}$ calculated with (6)

(b)

FIgURE 9: (a) Comparison between experimental and calculated temperatures and (b) residual temperatures.

Figure 11 shows the average maximum temperature at the cutting interface for the cutting conditions defined in Tables 3 to 5 . These values were calculated using the numerical methodology proposed in this work (considering (6) and (7), uniform and exponential heat flux) and measured with the experimental technique TWTT [8].

As in Trent [15], the temperature at the cutting interface increases with the increase in cutting parameters. In other words, increasing the cutting parameters increases the chiptool contact area and the rate of deformation, thus generating more energy and consequently higher temperatures at the cutting interface.

Figure 11 also shows the difference between temperature profiles measured with TWTT and calculated by numerical techniques. With the experimental TWTT technique as a reference, there is a significant difference between experimental and numerical temperatures. Figure 11(c) shows that this difference decreases when the cutting speed increases. Trent [15] showed that cutting speeds between 100 and $200 \mathrm{~m} / \mathrm{min}$ give temperatures at cutting interface between $600^{\circ} \mathrm{C}$ and $800^{\circ} \mathrm{C}$, which agrees with the values obtained in this work.

Both TWTT and numerical methodology have sources of errors which can influence directly the measured and calculated temperatures which can justify the differences shown in Figure 11.

For the numerical methodology the uncertainties are related to the dimensions and the simplifications adopted to simulate the thermal behavior of tool, the correct identification of the thermal properties of the high speed steel, the convective heat transfer coefficient, the measured temperatures during turning, and the correct identification of the chip-tool contact area for each cutting condition.
According to Evangelista Luiz [8] the uncertainties in TWTT technique are related to the calibration of the system and the assembly of the experimental components. The TWTT basically consists of an electric circuit which involves the tool, the workpiece, and the lathe. The tool and the workpiece forming the thermocouple had to be previously calibrated as any conventional sensor and the experimental procedure is strongly dependent on the equipments and the ability of the operator. Besides, during turning, a mercury chamber had to be used to connect the components of the system due to the rotation of the workpiece as shown in Figure 5(a). Also the attrition between tool and workpiece generates noise in the signal of the temperature that had to be minimized using statistical tools to remove excessive noise and to define the mean temperature and the standard deviation.

\section{Conclusions}

This work is an interdisciplinary study involving two major areas of mechanical engineering: heat transfer and manufacturing processes. Based on the knowledge of these two areas, a new computational algorithm for solving problems of heat transfer applied to manufacturing processes, focusing on turning process, was developed.

The simulations optimize the numerical model proposed analyzing the numerical mesh, computational cost, convergence, quality of numerical results, and possible sources of error in order to obtain a favorable cost-benefit solution of the thermal problem. Furthermore, in experiments in this study, it was sought to minimize the likely sources of experimental errors. 


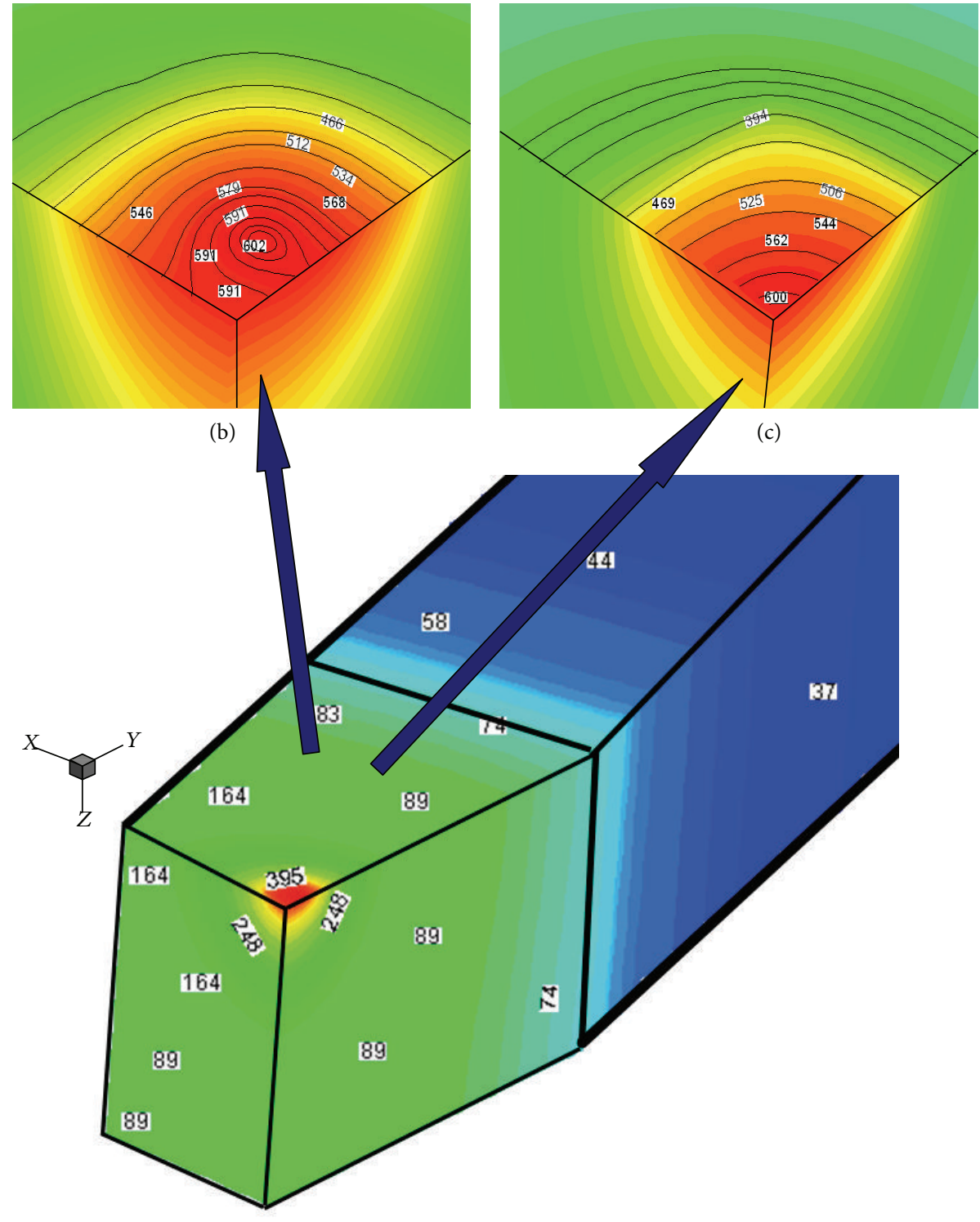

(a)

FIGURE 10: Temperature profile for feed rate $f=0.138 \mathrm{~mm} / \mathrm{rot}$, cutting speed $V c=142 \mathrm{~m} / \mathrm{min}(900 \mathrm{rpm})$, and cutting depth ap $=1.0 \mathrm{~mm}$ : (a) tool, (b) cutting interface temperatures for exponential heat flux (7), and (c) cutting interface temperatures for uniform heat flux (6).

Regarding the thermal effects studied, it was possible to calculate and analyze the three-dimensional temperature distribution in the thermal machining model as well as at chiptool interface. The numerically temperatures were compared with experimental data which can increase the reliability and credibility of the results found. Besides temperature, in this study the heat flux at the contact interface, which allowed a quantitative analysis of the thermal energy generated in the machining process, was estimated.

This work studied the thermal effects during turning and also analyzes the influence of the cutting conditions (cutting speed, feed rate, and depth of cut) on the temperature generated at chip-tool interface. Analyzing the results, as in the literature, the temperature at the cutting interface increases with the increase in cutting conditions. The results do not fit perfectly with those presented by Evangelista Luiz [8], using the experimental method of tool-workpiece thermocouple technique. This fact is attributed to the possible sources of error in each methodology which have direct influence on the results. Thus, there is no existing technique that can be universally accepted as a standard. There are attempts to understand the fundamentals of the thermal exchanges during turning and it is believed that the understanding is the next step to predict the performance of a manufacturing process [16].

\section{Conflict of Interests}

The authors declare that there is no conflict of interests regarding the publication of this paper. 

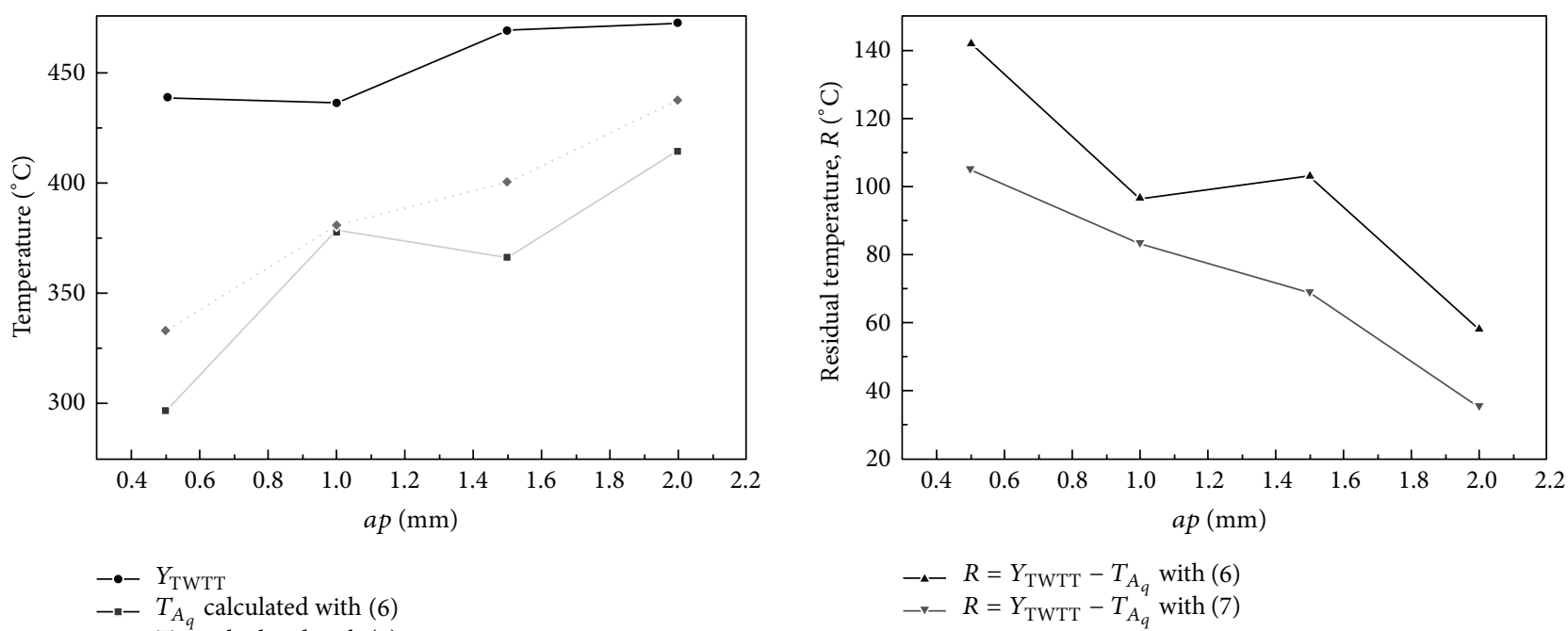

(a)
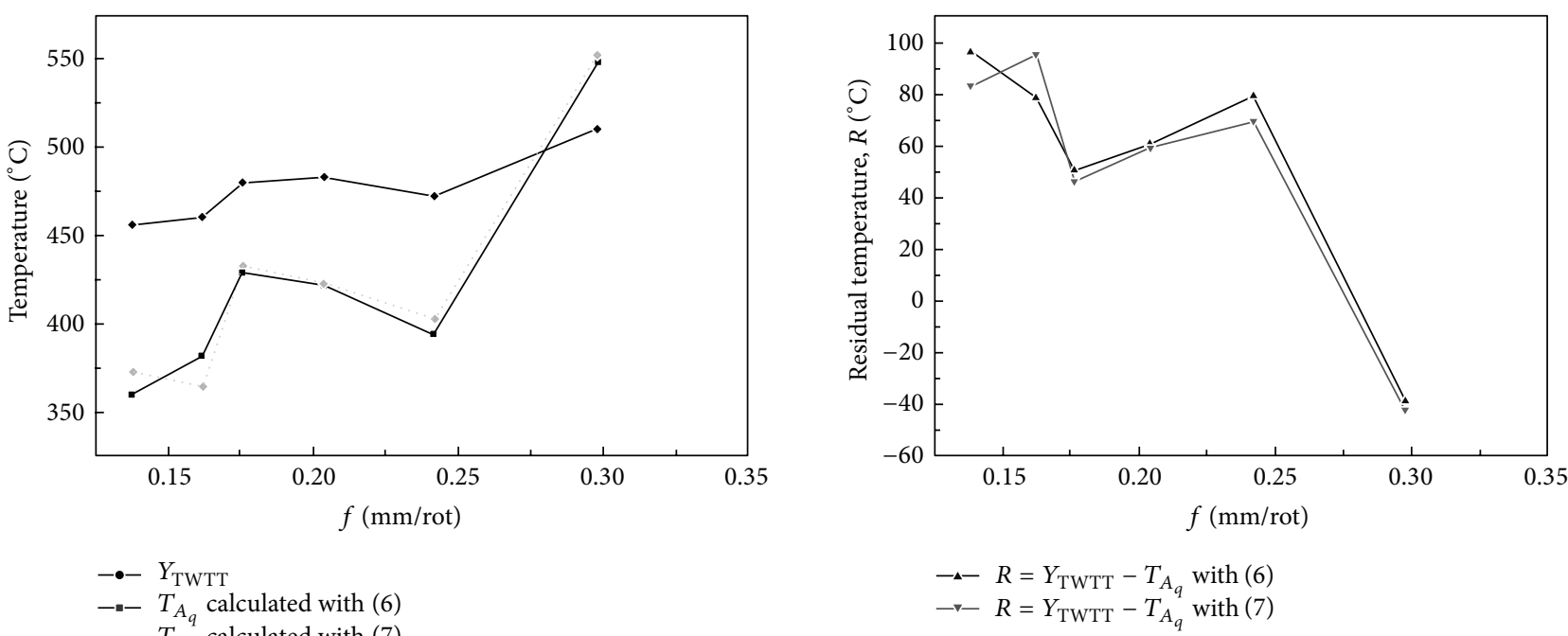

(b)
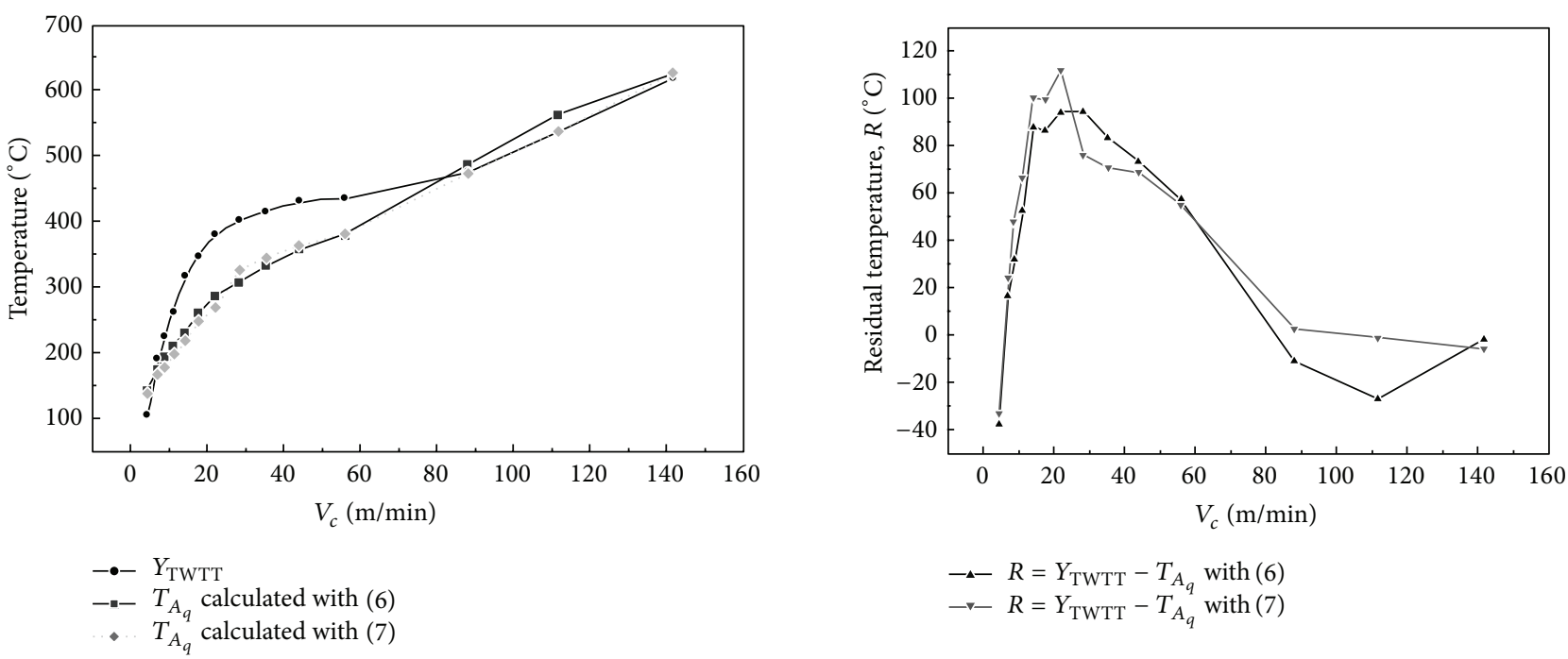

(c)

FIGURE 11: Chip-tool interface temperature and residual for TWTT and data from (a) Table 3, (b) Table 4, and (c) Table 5. 


\section{Acknowledgments}

The authors thank CNPq, FAPEMIG, and CAPES for the financial support, without which this work would not be possible.

\section{References}

[1] W. C. Chen, C. C. Tsao, and P. W. Liang, "Determination of temperature distributions on the rake face of cutting tools using a remote method," International Communications Heat Mass Transfer, vol. 24, pp. 161-170, 1997.

[2] J. V. Beck, B. Blackwell, and C. St. Clair, Inverse Heat Conduction: Ill-Posed Problems, Wiley-Interscience, New York, NY, USA, 1985.

[3] M. Lazard and P. Corvisier, "Inverse method for transient temperature estimation during machining," in Proceedings of the 5th International Conference on Inverse Problems in Engineering: Theory and Practice, Cambridge, UK, 2005.

[4] J. Yvonnet, D. Umbrello, F. Chinesta, and F. Micari, "A simple inverse procedure to determine heat flux on the tool in orthogonal cutting," International Journal of Machine Tools and Manufacture, vol. 46, no. 7-8, pp. 820-827, 2006.

[5] K. A. Woodbury, S. Duvvuri, Y. K. Chou, and J. Liu, "Use of evolutionary algorithms to determine tool heat fluxes in a machining operation," in Proceedings of the Inverse Problems Design and Optimization Symposium (IPDO '), Miami Beach, Fla, USA, 2007.

[6] D. Ulutan, I. Lazoglu, and C. Dinc, “Three-dimensional temperature predictions in machining processes using finite difference method," Journal of Materials Processing Technology, vol. 209, no. 2, pp. 1111-1121, 2009.

[7] F. Samadi, F. Kowsary, and A. Sarchami, "Estimation of heat flux imposed on the rake face of a cutting tool: a nonlinear, complex geometry inverse heat conduction case study," International Communications in Heat and Mass Transfer, vol. 39, no. 2, pp. 298-303, 2012.

[8] N. Evangelista Luiz, Usinabilidade do aço de corte fácil baixo carbono ao chumbo abnt $12 l 14$ com diferentes níveis de elementos químicos residuais (cromo, níquel e cobre) [doctorate thesis], School of Mechanical Engineering, Federal University of Uberlândia, Uberlândia, Brazil, 2007.

[9] S. R. Carvalho, S. M. M. Lima e Silva, A. R. Machado, and G. Guimarães, "Temperature determination at the chip-tool interface using an inverse thermal model considering the tool and tool holder," Journal of Materials Processing Technology, vol. 179, no. 1-3, pp. 97-104, 2006.

[10] R. F. Brito, S. R. Carvalho, S. M. M. Lima e Silva, and J. R. Ferreira, "Thermal analysis in TIN and $\mathrm{AL}_{2} \mathrm{O}_{3}$ coated iso $\mathrm{K} 10$ cemented carbide cutting tools using Design of Experiment (DoE) methodology," Journal of Machining and Forming Technologies, vol. 3, pp. 1-12, 2011.

[11] R. F. Brito, S. R. D. Carvalho, S. M. M. D. Lima e Silva, and J. R. Ferreira, "Thermal analysis in coated cutting tools," International Communications in Heat and Mass Transfer, vol. 36, no. 4, pp. 314-321, 2009.

[12] P. F. B. Sousa, S. R. Carvalho, and G. Guimarães, "Dynamic observers based on Green's functions applied to 3D inverse thermal models," Inverse Problems in Science and Engineering, vol. 16, no. 6, pp. 743-761, 2008.
[13] Taylor Specials Steels Ltda, 2005, http://www.taylorspecialsteels.co.uk/pdfdownload/m35.pdf\#search='M35\%20thermal \%20properties.

[14] P. A. Dearnley, "New technique for determining temperature distribution in cemented carbide cutting tools," Metals Technology, vol. 10, no. 6, pp. 205-214, 1983.

[15] E. M. Trent, Metal Cutting, Butterworths, London, UK, 2nd edition, 1984.

[16] A. R. Machado and M. B. Silva, Usinagem dos Metais, 8th edition, 2004 


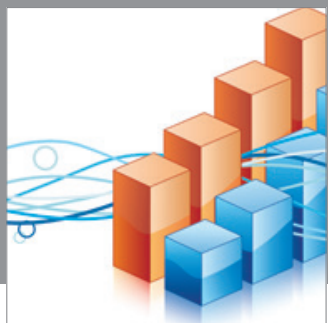

Advances in

Operations Research

mansans

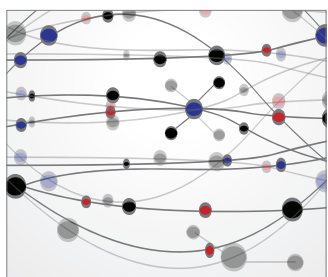

The Scientific World Journal
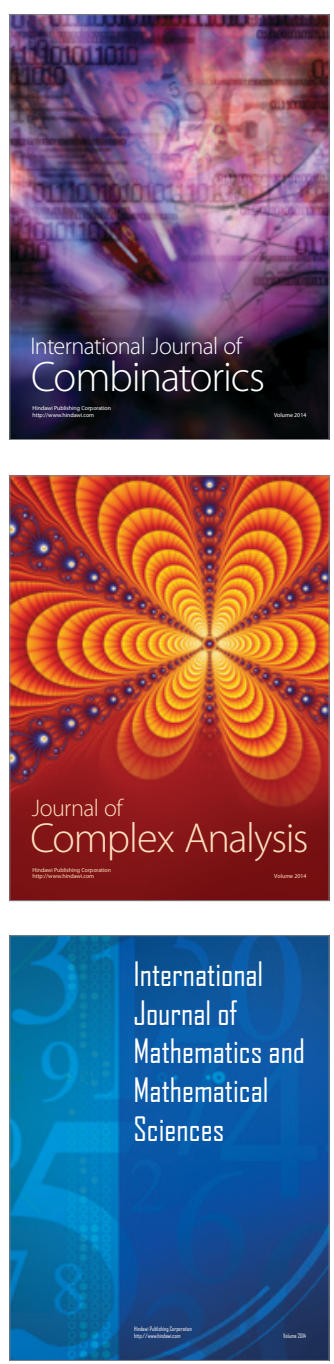
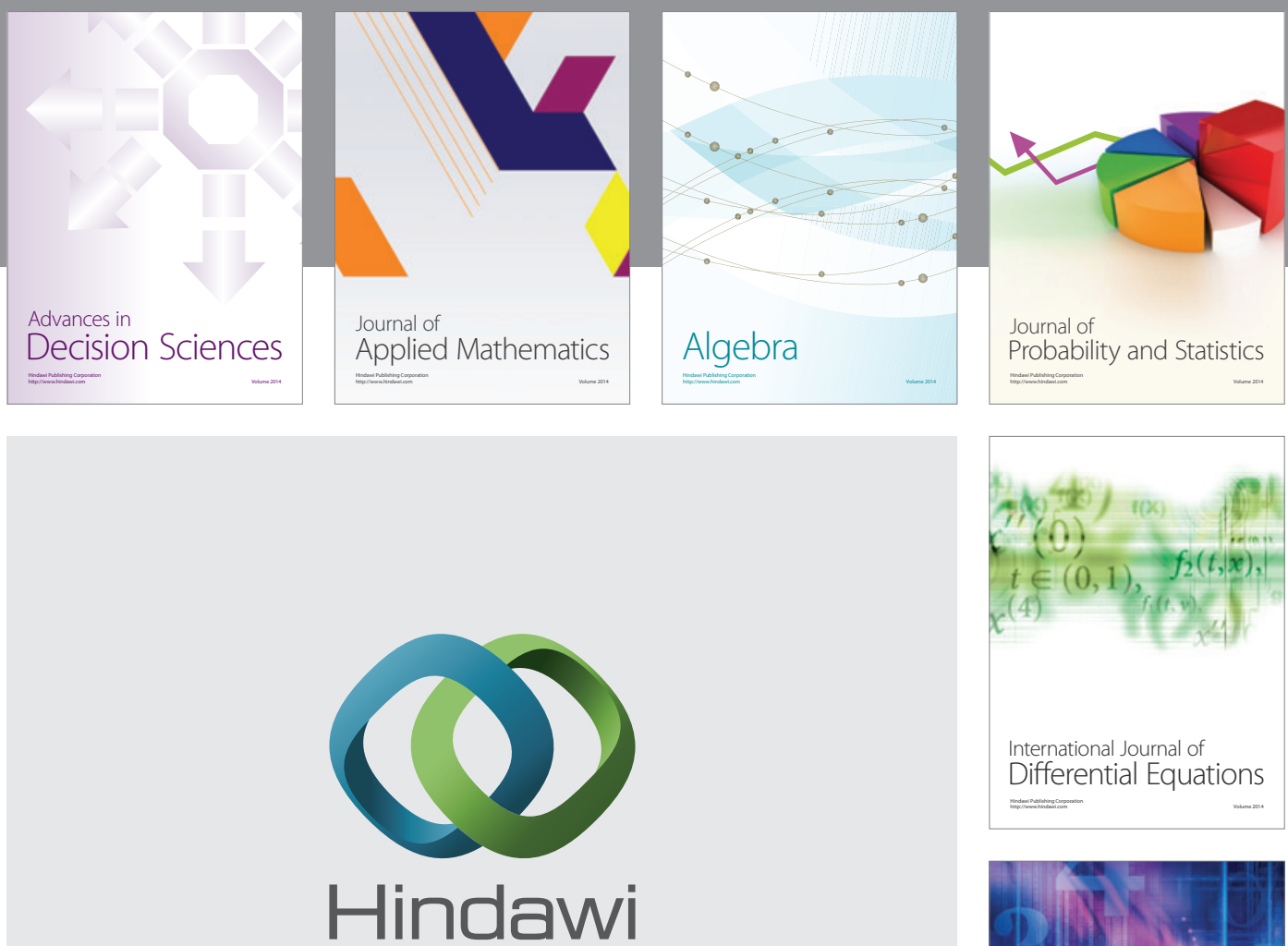

Submit your manuscripts at http://www.hindawi.com
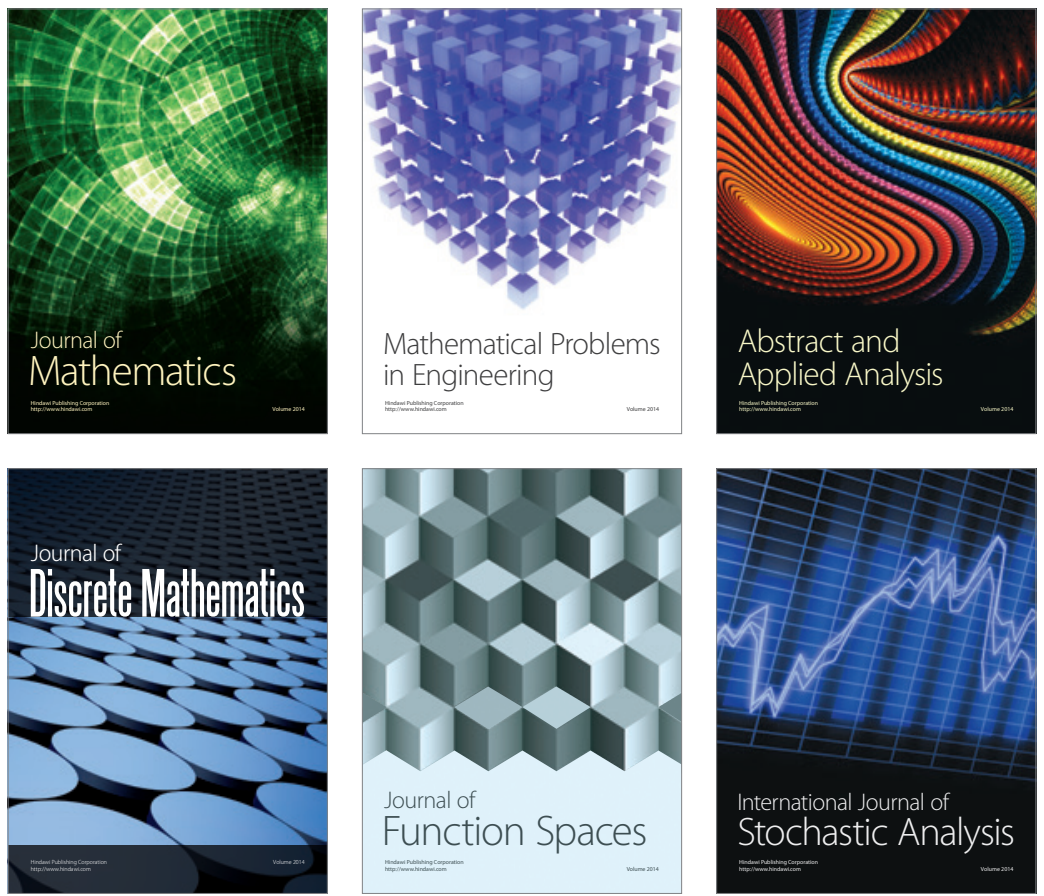

Journal of

Function Spaces

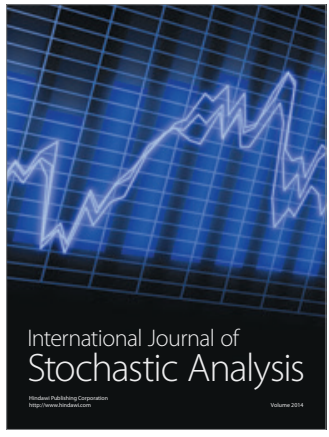

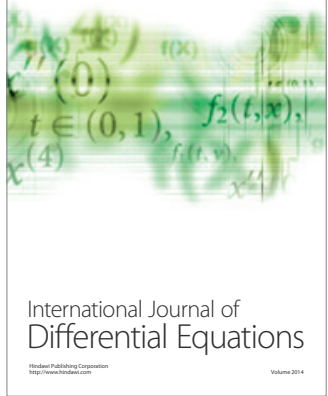
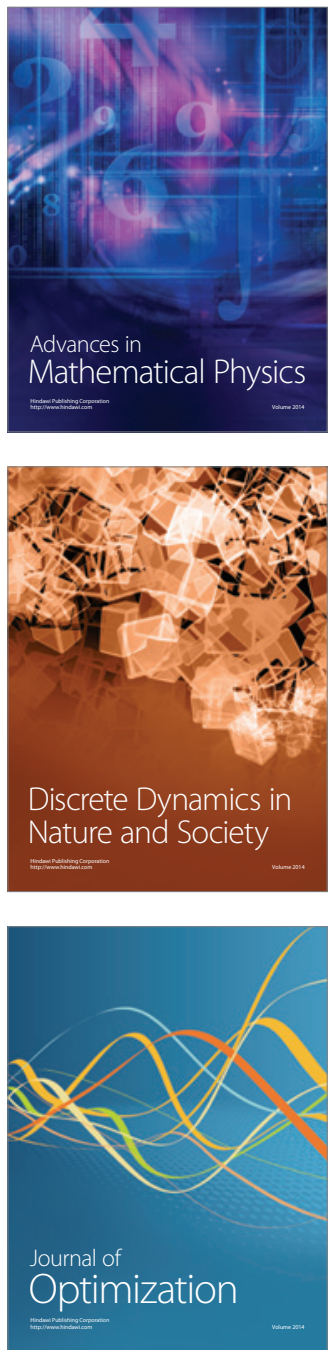